\title{
Fungi from Asian Karst formations I. Pestalotiopsis photinicola sp. nov., causing leaf spots of Photinia serrulata
}

\author{
Chen YY ${ }^{1,2,3}$, Maharachchikumbura $\mathrm{SSN}^{4}$, Liu JK ${ }^{3,5}$, Hyde $\mathrm{KD}^{6}$, Nanayakkara \\ $\mathbf{R R}^{3}$, Zhu GS ${ }^{2}$, Liu $\mathbf{Z Y}^{3 *}$
}

\author{
${ }^{1}$ Agricultural College of Guizhou University, Guiyang, 550006, P.R. China \\ ${ }^{2}$ Guizhou Institute of Crop Genetic Resources, Guiyang, 550006, P.R. China \\ ${ }^{3}$ Guizhou Key Laboratory of Agricultural Biotechnology, Guizhou Academy of Agricultural Sciences, Guiyang 550006, \\ P. R. China \\ ${ }^{4}$ Department of Crop Sciences, College of Agricultural and Marine Sciences, Sultan Qaboos University, PO Box 8,123 \\ Al Khoud, Oman \\ ${ }^{5}$ Guizhou Institute of Biotechnology, Guiyang, 550006, P.R. China. \\ ${ }^{6}$ Center of Excellence in Fungal Research, Mae Fah Luang University, Chiang Rai 57100. Thailamd.
}

Chen YY, Maharachchikumbura SSN, Liu JK, Hyde KD, Nanayakkara RR, Zhu GS, Liu ZY 2017 - Fungi from Asian Karst formations I. Pestalotiopsis photinicola sp. nov., causing leaf spots of Photinia serrulata. Mycosphere 8(1), 103-110, Doi 10.5943/mycosphere/8/1/9

\begin{abstract}
This is the first in a series of papers on the fungi growing on plants in the Karst formations of the Asian region. In this study, we collected leaf specimens of Photinia with numerous spots from Guiyang Botanical Gardens, Guiyang, China. A combination of morphological characters, together with analyses of combined ITS, TUB and TEF sequence data, distinguished the taxon as a new species of Pestalotiopsis. The new taxon is herein described as Pestalotiopsis photinicola and discussed in relation to the most related taxa.
\end{abstract}

Key words - Karst fungi-new species-phylogeny-taxonomy

\section{Introduction}

Karst topography is a landscape formed from the dissolution of soluble rocks such as limestone, dolomite, and gypsum and is characterized by underground drainage systems with sinkholes, dolines and caves (Gorbushina et al. 2003). Rainfall and temperatures vary greatly and the formations can be regarded as extreme habitats, especially when soils are sparse. The south China Karst system represents three of the world's most spectacular examples of humid tropical to sub-tropical karst landscapes and extends over a surface of 500,000 square kilometers and lies mainly in the provinces of Guizhou, Yunnan and Guangxi (World Wildlife Fund 2016). The Karst formations are also found in Cambodia, Laos, Malaysia, Myanmar, Thailand and Vietnam (Gunn 2004). Guizhou Province is located in the center of the Southeast Asian Karst Region where it has the most developed karstification, and most diverse karst types, which is also the largest karst formation in the world (Han \& Liu 2004). This area has richest biodiversity; there are more than 6000 higher plant species, which include Cathaya argyrophyll, Cycas guizhouensis, Davidia involucrata and Taxus chinensis, threatened and endemic species (http://www.worldwildlife.org/ ecoregions/pa0101). 
The genus Pestalotiopsis Steyaert (1949) is an appendage-bearing, conidial, asexual taxon (coelomycetes) in the family Pestalotiopsidaceae (Hu et al. 2007, Maharachchikumbura et al. 2012, 2015, 2016, Senanayake et al. 2015), and is common in tropical and temperate ecosystems (Maharachchikumbura et al. 2014). Species of Pestalotiopsis cause a variety of diseases and are often isolated as endophytes or saprobes plants (Zhang et al. 2012 a, b, 2013, Maharachchikumbura et al. 2013 a, b, c). Pestalotiopsis consists of around 300 names (Index Fungorum 2017) and there are various reports that Pestalotiopsis species produce a diverse array of chemical compounds (Xu et al. 2010, Maharachchikumbura et al. 2011).

We are carrying out a survey of diseases of native, ornamental and medicinal plants in the Karst regions of Asia. The aim of this paper is to introduce a new species of Pestalotiopsis from Photinia serrulata, which is a very popular ornamental shrub in China and it is commonly known as Chinese Photinia. The taxon associated with the disease was isolated into culture, where it also produced a Pestalotiopsis asexual morph. Molecular and morphological analysis showed this fungus to be a new species of Pestalotiopsis and it is described here as Pestalotiopsis photinicola.

\section{Materials \& Methods}

\section{Isolation and morphological studies}

Fresh specimens were obtained from leaf spots on living leaves of Photinia serrulata collected from Guiyang Botanical Gardens, Guiyang Province, China. To induce sporulation, infected leaves were placed in sterilized Petri-dishes with moistened sterile filter paper. The Pestalotiopsis species present on the samples was isolated from single spores using the method of Chomnunti et al. (2014). The pure cultures were incubated at room temperature for 2-5 days and sub-cultured onto fresh PDA. Colony colour on PDA was determined with the colour charts of Rayner (1970). Observations were made using a Motic SMZ-168 Series stereomicroscope and photographed by a Nikon E80i microscope-camera system. Measurements were made with the Tarosoft (R) Image Frame Work (Liu et al. 2010). Facesoffungi numbers are provided as detailed in Jayasiri et al. (2015). Type materials are deposited at the herbarium of Guizhou Academy of Agriculture Sciences (GZAAS). Fungi isolated in our study were deposited at Guizhou Culture Collection, Guiyang, China (GZCC).

\section{DNA extraction and PCR condition and phylogenetic analysis}

Total genomic DNA was extracted from fresh fungal mycelia $(500 \mathrm{mg})$ scraped from the margin of a colony on a PDA plate incubated at $25^{\circ} \mathrm{C}$ for $7-10$ days. The ITS and $5.8 \mathrm{~S}$ region of rDNA molecule was amplified using primer pairs ITS4 and ITS5 (White et al. 1990), $\beta$-tubulin gene region was amplified with primer pairs BT2A and BT2B (Glass \& Donaldson 1995, O'Donnell \& Cigelnik 1997) and tefl was amplified using the primer pairs EF1-526F and EF11567R (Rehner 2001). The thermal cycling programs are followed in Maharachchikumbura et al. (2012). Sequencing of the PCR amplicons was conducted using the same primers as those used for the amplification reactions. The PCR products were verified by staining with Goldview (Guangzhou Geneshun Biotech, China) on $1 \%$ agarose electrophoresis gels. DNASTAR Lasergene SeqMan Pro v.8.1.3 was used to obtain consensus sequences from sequences generated from forward and reverse primers and these were subsequently lodged with GenBank (Table 1).

Most of the taxa used in this study are derived from Maharachchikumbura et al. (2012, 2013a,b,c, 2014) and Zhang et al. (2012a,b, 2013). Multiple sequence alignments were generated with MAFFT v.7 (http://mafft. cbrc.jp/alignment/server/ index.html); the alignment was visually improved with MEGA v.5.2.2 (Kumar et al. 2012). Phylogenetic analyses of the sequence data consisted of maximum likelihood (ML) analyses of the combined aligned dataset using raxmlGUI v.1.3 (Silvestro \& Michalak 2011). The optimal ML tree search was conducted with 1000 separate runs, using the default algorithm of the program from a random starting tree for each run. The final tree was selected among suboptimal trees from each run by comparing likelihood scores under the 
GTRGAMMA substitution model. The resulting trees were printed with FigTree v.1.4.0 (http://tree. bio.ed.ac.uk/software/figtree/) and the layout was made with Adobe Illustrator CS v.6.

Table 1 GenBank Accession numbers of the sequences used in phylogenetic analysis

\begin{tabular}{|c|c|c|c|c|}
\hline \multirow[t]{2}{*}{ Species } & \multirow[t]{2}{*}{ Strain No. } & \multicolumn{3}{|c|}{ GenBank Accession Numbers. } \\
\hline & & ITS & TUB & TEF \\
\hline Pestalotiopsis adusta & ICMP 6088 & JX399006 & JX399037 & JX399070 \\
\hline P. australis & CBS 114193 & KM199332 & KM199383 & KM199475 \\
\hline P. arceuthobii & CBS 434.65 & KM199341 & KM199427 & KM199516 \\
\hline$P$. arengae & CBS 331.92 & KM199340 & KM199426 & KM199515 \\
\hline P. australasiae & CBS 114126 & KM199297 & KM199409 & KM199499 \\
\hline P. biciliata & CBS 790.68 & KM199305 & KM199400 & KM199507 \\
\hline P. biciliata & CBS 124463 & KM199308 & KM199399 & KM199505 \\
\hline P. biciliata & CBS 236.38 & KM199309 & KM199401 & KM199506 \\
\hline P. brassicae & CBS 17026 & KM199379 & ---- & KM199558 \\
\hline P.camelliae & MFLUCC 12-0277 & JX399010 & JX399041 & JX399074 \\
\hline P. clavata & MFLUCC 12-0268 & JX398990 & JX399025 & JX399056 \\
\hline P. chamaeropis & CBS 186.71 & KM199326 & KM199391 & KM199473 \\
\hline P. colombiensis & CBS 118553 & KM199307 & KM199421 & KM199488 \\
\hline P. digitalis & ICMP 5434 & KP781879 & KP781883 & \\
\hline P. diploclisiae & CBS 115587 & KM199302 & KM199419 & KM199486 \\
\hline P.diversiseta & MFLUCC 12-0287 & JX399009 & JX399040 & JX399073 \\
\hline P. dracontomelon & MFUCC 10-0149 & KP781877 & & KP781880 \\
\hline P. ericacearum & IFRDCC 2439 & KC537807 & KC537821 & KC537814 \\
\hline$P$. furcata & MFLUCC 12-0054 & JQ683724 & JQ683708 & JQ683740 \\
\hline P. gaultheria & IFRD 411-014 & KC537805 & КС537819 & KC537812 \\
\hline P. grevilleae & CBS 114127 & KM199300 & KM199407 & KM199504 \\
\hline P. hawaiiensis & CBS 114491 & KM199339 & KM199428 & KM199514 \\
\hline P. hollandica & CBS 265.33 & KM199328 & KM199388 & KM199481 \\
\hline P. humus & CBS 336.97 & KM199317 & KM199420 & KM199484 \\
\hline P. inflexa & MFLUCC 12-0270 & JX399008 & JX399039 & JX399072 \\
\hline P. intermedia & MFLUCC 12-0259 & JX398993 & JX399028 & JX399059 \\
\hline P. intermedia & MFLUCC 12-0259 & JX398993 & JX399028 & JX399059 \\
\hline P. italiana & MFLUCC 12-0657 & KP781878 & KP781882 & KP781881 \\
\hline P. jesteri & CBS 109350 & KM199380 & KM199468 & KM199554 \\
\hline P. kenyana & CBS 442.67 & KM199302 & KM199395 & KM199502 \\
\hline P. knightiae & CBS 114138 & KM199310 & KM199408 & KM199497 \\
\hline P. licualacola & HGUP 4057 & KC436006 & KC481683 & KC481684 \\
\hline$P$. linearis & MFLUCC 12-0271 & JX398992 & JX399027 & JX399058 \\
\hline P. malayana & CBS 102220 & KM199306 & KM199411 & KM199482 \\
\hline P. monochaeta & CBS 144.97 & KM199327 & KM199386 & KM199479 \\
\hline P. novae-hollandiae & CBS 130973 & KM199337 & KM199425 & KM199511 \\
\hline P. oryzae & CBS 353.69 & KM199299 & KM199398 & KM199496 \\
\hline P. papuana & CBS 331.96 & KM199321 & KM199413 & KM199491 \\
\hline P. parva & CBS 265.37 & KM199312 & KM199404 & KM199508 \\
\hline P. photinicola & GZCC 16-0028 & KY092404 & KY047663 & KY047662 \\
\hline P. portugalica & CBS 393.48 & KM199335 & KM199422 & KM199510 \\
\hline P. rhodomyrtus & HGUP 4230 & KF412648 & KF412642 & KF412645 \\
\hline P. rosea & MFLUCC 12-0258 & JX399005 & JX399036 & JX399069 \\
\hline P. scoparia & CBS 176.25 & KM199330 & KM199393 & KM199478 \\
\hline P. shorea & MFLUCC 12-0314 & KJ503811 & KJ503814 & KJ503817 \\
\hline P. spathulata & CBS 356.86 & KM199338 & KM199423 & KM199513 \\
\hline P. trachicarpicola & OP068 & JQ845947 & JQ845945 & JQ845946 \\
\hline P. telopeae & CBS 114161 & KM199296 & KM199403 & KM199500 \\
\hline P.unicolor & MFLUCC 12-0276 & JX398999 & JX399030 & 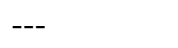 \\
\hline P. verruculosa & MFLUCC 12-0274 & JX398996 & ---- & JX399061 \\
\hline Neopestalotiopsis & NN047136 & JX398982 & JX399017 & JX399048 \\
\hline
\end{tabular}




\section{Results}

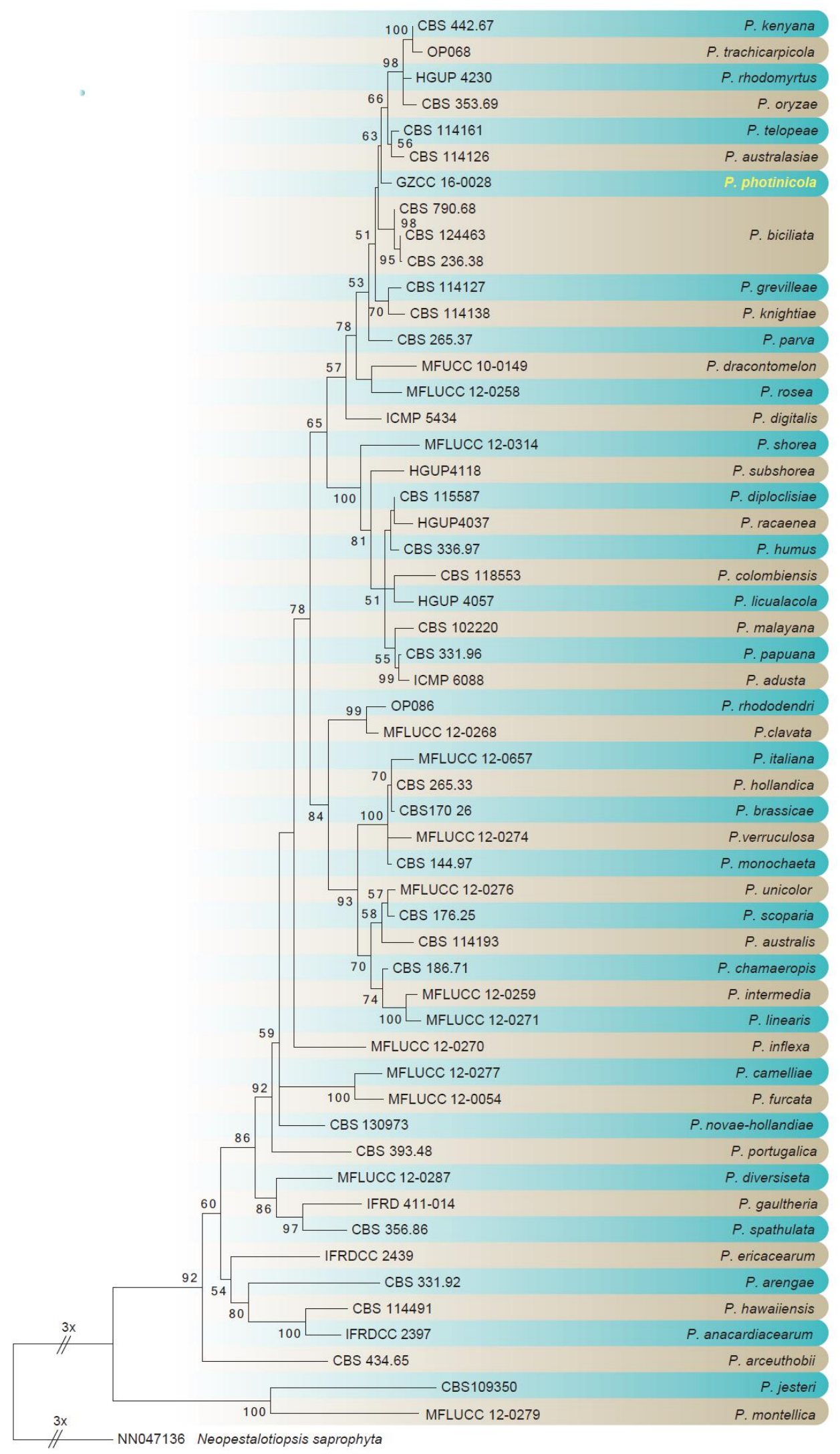

Fig 1. Maximum likelihood (ML) majority rule consensus tree for the analyzed Pestalotiopsis isolates. RAxML bootstrap support values (ML > 50\%) are given at the nodes and new isolates are in yellow. The scale bar represents the expected number of changes per site. The tree was rooted to Neopestalotiopsis saprophytica. 


\section{Phylogenetic analyses}

The aligned data matrix for combined ITS, $\beta$-tubulin and tef1 datasets consisted of 55 sequences representing 34 isolates of Pestalotiopsis, with Neopestalotiopsis saprophyta as the outgroup taxon, and consisted of 1,633 total characters, including gaps. Our phylogenetic analyses showed that the isolate of $P$. photinicola (GZCC 16-0028) formed a clade with moderate statistical support (60), and show close phylogenetic relationship with $P$. telopeae, $P$. australasiae and $P$. biciliata, but formed a distinct clade within the genus and herein we introduce it as a new species $P$. photinicola.

\section{Taxonomy}

Pestalotiopsis photinicola Y.Y. Chen, K.D. Hyde, J.K. Liu; \& Maharachch., sp. nov. Index Fungorum number: IF552562, Facesoffungi number: FoF 02914, Fig 2

Etymology - named after the host from which the holotype was isolated

Holotype: GZAAS 16-0019

Associated with leaf spots of Photinia serrulata. Asexual morph: Conidiomata, brown, epidermal to subepidermal, separate or confluent, dehiscence irregular, 150-270 $\mu \mathrm{m}$ diameter $(\bar{x}=$ $215 \mu \mathrm{m}, \mathrm{n}=20$ ). Conidiophores most often reduced to conidiogenous cells, simple or branched, hyaline, smooth-walled. Conidiogenous cells discrete, hyaline, 1-celled, branched or separate at the base, formed from the upper cells of the pseudoparenchyma, collarette present and not flared. Conidia 18-24 $\times 4-5 \mu \mathrm{m}(\bar{x}=21.5 \mu \mathrm{m}, \mathrm{n}=20)$, fusiform, straight to slightly curved, 4-septate; basal cell obconic, hyaline, thin- and smooth-walled, 5.5-8 $\mu \mathrm{m}$ long $(\bar{x}=6.6 \mu \mathrm{m}, \mathrm{n}=10)$; three median cells, concolourous, brown, septa and periclinal walls darker than rest of the cell, $11-15 \mu \mathrm{m}$ long $(\bar{x}=13 \mu \mathrm{m}, \mathrm{n}=10)$; second cell from base $4.5-5 \mu \mathrm{m}$ long $(\bar{x}=4.7 \mu \mathrm{m}, \mathrm{n}=10)$; third cell 4.5-5.5 $\mu \mathrm{m}$ long $(\bar{x}=5 \mu \mathrm{m}, \mathrm{n}=10)$; fourth cell 5-5.5 $\mu \mathrm{m}$ long $(\bar{x}=5.2 \mu \mathrm{m}, \mathrm{n}=10)$; apical cell, hyaline, conic to subcylindrical, $3-5 \mu \mathrm{m}$ long $(\bar{x}=4 \mu \mathrm{m}) ; 1-3$ tubular apical appendages (mostly 3 ), arising from the apex, $12-22 \mu \mathrm{m}$ long $(\bar{x}=17.5 \mu \mathrm{m})$; basal appendage single, tubular, unbranched, centric, $4-8 \mu \mathrm{m}$ long $(\bar{x}=6 \mu \mathrm{m})$. Sexual morph: Undetermined.

Culture characteristics - Colonies attaining 40-50 mm diameter after 7 days at $25{ }^{\circ} \mathrm{C}$ on PDA, edge irregular, white, dense aerial mycelium on surface, fruiting bodies black, gregarious; reverse of culture yellow-orange.

Material examined - CHINA. Guizhou Province, Guiyang Botanical Gardens, on leaves of Photinia serrulata, October 2015. Y.Y. Chen (GZAAS 16-0019; holotype), ex-type living culture GZCC 16-0028.

\section{Discussion}

In this study, one new species, Pestalotiopsis photinicola from disease leaves of Photinia serrulata from Guizhou Province, China is characterized in terms of morphology and phylogeny.

Pestalotiopsis photinicola is morphologically (Fig. 2) and phylogenetically (Fig. 1) distinct from other species in the genus. It is morphologically similar to P. australasiae $(24.5-29 \times 6.5-8$ $\mu \mathrm{m})$, P. biciliata $(22-28.5 \times 6-7.5 \mu \mathrm{m})$ and P. telopeae $(24.5-31 \times 6-8 \mu \mathrm{m})$ (Maharachchikumbura et al. 2014). However, Pestalotiopsis photinicola can clearly be distinguished from these species by its smaller conidia $(18-24 \times 4-5 \mu \mathrm{m})$. Pestalotiopsis photinicola is morphologically most similar to P. chamaeropis (Maharachchikumbura et al., 2014); however, the molecular analysis showed that they are phylogenetically distinct (Fig. 1).

Species of Pestalotiopsis are important as phytopathogens (Maharachchikumbura et al. 2012) and many species have been named according to their host association (Maharachchikumbura et al. 2011) and only a small number of characters are available to distinguish them reliably (Maharachchikumbura et al. 2013). Use of ITS sequences alone does not resolve pestalotiopsis-like taxa well, however, combined gene (ITS, $\beta$-tubulin and tefl) analyses have resolved species successfully (Maharachchikumbura et al. 2012) and it works for the present study. 

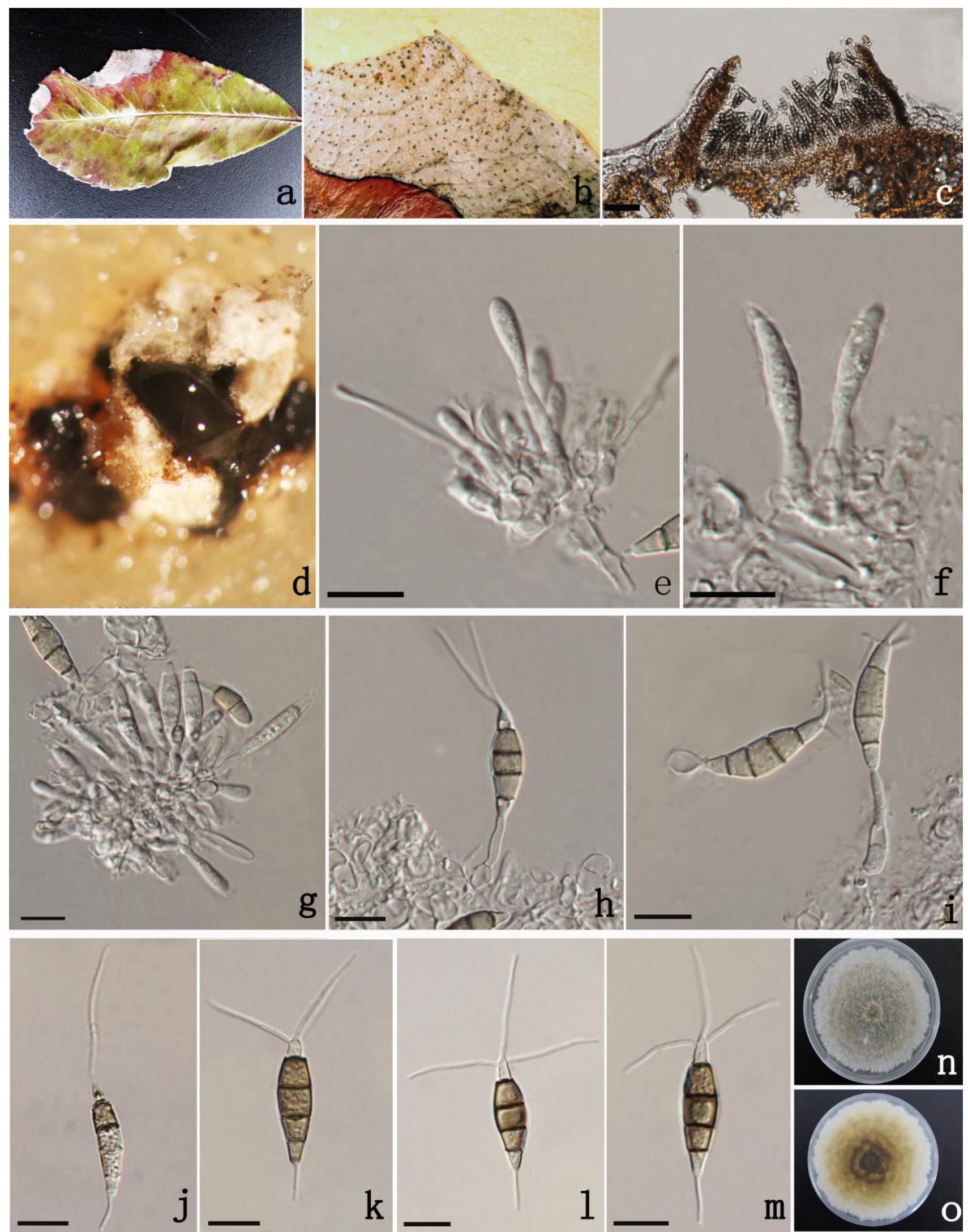

Fig. 2 Pestalotiopsis photinicola (holotype, GZAAS 16-0019). a, b. Leaf spot on living leaves of Photinia serrulata. c. Section of conidioma. d. Conidiomata on PDA. e-i. Conidiogenous cells and developing conidia. j-m. Conidia. Scale bars: $\mathrm{c}=50 \mu \mathrm{m}$, e-m $=10 \mu \mathrm{m}$

\section{Acknowledgments}

We would like to thank the Research of Featured Microbial Resources and Diversity 
Investigation in Southwest Karst area (Project No. 2014FY120100) for financial support. J.K Liu would like to thank the Phylogeny and Biodiversity of Botryosphaeriaceae in Southwest China (QianKeHe LH 2015-7061). Y.Y Chen is grateful J.F Zhang for his valuable suggestions.

\section{References}

Chomnunti P, Schoch CL, Aguirre-Hudson B, Ko Ko TW et al. 2011 - Capnodiaceae. Fungal Diversity 51, 103-134.

Glass NL, Donaldson GC. 1995 - Development of primer sets designed for use with the PCR to amplify conserved genes from filamentous ascomycetes. Applied and Environmental Microbiology 61, 1323-1330.

Gorbushina AA, Whitehead K, Dornieden T, Niesse A et al. 2003 - Black fungal colonies as units of survival: hyphal mycosporines synthesized by rock-dwelling microcolonial fungi. Canadian Journal of Botany 81, 131-138.

Gunn J. 2004 - Encyclopedia of Caves and Karst Science, $2^{\text {nd }}$ edition, Taylor and Francis Group 29 West 35 Street New York.

Han GL, Liu CQ. 2004 - Water geochemistry controlled by carbonate dissolution: a study of the river waters draining karst-dominated terrain, Guizhou Province, China. Chemical Geology 204, 1-21.

Hu HL, Jeewon R, Zhou DQ, Zhou TX, Hyde KD 2007 - Phylogenetic diversity of endophytic Pestalotiopsis species in Pinus armandii and Ribes spp.: evidence from rDNA and $\beta$-tubulin gene phylogenies. Fungal Diversity 24, 1-22.

Index Fungorum 2017 - www.indexfungorum.org

Jayasiri SC, Hyde KD, Ariyawansa HA, Bhat J et al. 2015 - The Faces of Fungi database: fungal names linked with morphology, phylogeny and human impacts. Fungal Diversity 74, 3-18.

Kumar S, Stecher G, Peterson D. 2012 - MEGA-CC: computing core of molecular evolutionary genetics analysis program for automated and iterative data analysis. Bioinformatics $28,2685-$ 2686.

Liu JK, Chomnunti P, Cai L, Phookamsak R et al. 2010 - Phylogeny and morphology of Neodeightonia palmicola sp. nov. from palms. Sydowia 62, 261-276.

Maharachchikumbura SSN, Guo LD, Chukeatirote E, Bahkali AH, Hyde KD. 2011 Pestalotiopsis - morphology, phylogeny, biochemistry and diversity. Fungal Diversity 50, 167-187.

Maharachchikumbura SSN, Guo LD, Cai L, Chukeatirote E et al. 2012 - A multi-locus backbone tree for Pestalotiopsis, with a polyphasic characterization of 14 new species. Fungal Diversity $56,95-129$.

Maharachchikumbura SSN, Chukeatirote E, Guo LD, Crous PW et al. 2013a - Pestalotiopsis species associated with Camellia sinensis (tea) Mycotaxon 123, 47-61.

Maharachchikumbura SSN, Zhang YM, Wang Y, Hyde KD 2013b - Pestalotiopsis anacardiacearum sp. nov. (Amphisphaeriaceae) has an intricate relationship with Penicillaria jocosatrix the mango tip borer. Phytotaxa 99, 49-57.

Maharachchikumbura SSN, Guo LD, Chukeatirote E, McKenzie EHC, Hyde KD. 2013c - A destructive new disease of Syzygium samarangense in Thailand caused by the new species Pestalotiopsis samarangensis. Tropical Plant Pathology 38, 227-235.

Maharachchikumbura SSN, Hyde KD, Groenewald JZ, Xu JC, Crous PW. 2014 - Pestalotiopsis revisited. Studies in Mycology 79, 121-186.

Maharachchikumbura SSN, Camporesi E, Liu ZY, Hyde KD. 2015 - Seiridium venetum redescribed, and $S$. camelliae, a new species from Camellia reticulata in China. Mycological Progress $14,85$.

Maharachchikumbura SSN, Guo LD, Liu ZY, Hyde KD. 2016 - Pseudopestalotiopsis ignota and Ps. camelliae spp. nov. associated with grey blight disease of tea in China. Mycological Progress 15, 22. 
O’Donnell K, Cigelnik E. 1997 - Two divergent intragenomic rDNA ITS2 types within a monophyletic lineage of the fungus Fusarium are nonorthologous. Molecular Phylogenetics and Evolution 7, 103-116.

Rayner RW .1970 - A mycological colour chart. CMI and British Mycological Society, Kew, UK.

Rehner SA. 2001 - Primers for Elongation Factor 1-alpha (EF1 alpha). http://ocid.nacse.org/research/deephyphae/EF1primer.pdf

Senanayake IC, Maharachchikumbura SSN, Hyde KD, Bhat JD et al. 2015 - Towards unraveling relationships in Xylariomycetidae (Sordariomycetes). Fungal Diversity 73, 73-144.

Silvestro D, Michalak I. 2012 - raxmlGUI: a graphical front-end for RAxML. Organisms Diversity \& Evolution 12, 335-337.

Steyaert RL .1949 - Contributions à l'étude monographique de Pestalotia de Not. et Monochaetia Sacc. (Truncatella gen. nov. et Pestalotiopsis gen. nov.). Bull. Jard. Bot. Etat Bruxelles 19, 285-354.

White TJ, Bruns T, Lee S, Taylor JW. 1990 - Amplification and direct sequencing of fungal ribosomal RNA genes for phylogenetics. In: Innis MA, Gelfand DH, Sninsky JJ, White TJ (eds), PCR Protocols: a guide to methods and applications. Academic, New York, pp. 315322.

World Wildlife Fund (2016) http://www.worldwildlife.org/ecoregions/pa0101. (accessed: 30 May 2016).

Xu J, Ebada SS, Proksch P. 2010 - Pestalotiopsis a highly creative genus: chemistry and bioactivity of secondary metabolites. Fungal Diversity 44: 15-31.

Zhang YM Maharachchikumbura SSN, Tian Q, Hyde KD. 2013 - Pestalotiopsis species on ornamental plants in Yunnan Province, China. Sydowia 65, 59-74.

Zhang YM, Maharachchikumbura SSN, Wei JG, McKenzie EHC, Hyde KD. 2012 - Pestalotiopsis camelliae, a new species associated with grey blight of Camellia japonica in China. Sydowia 64, 335-344.

Zhang YM, Maharachchikumbura SSN, McKenzie EHC, Hyde KD. 2012 - A novel species of Pestalotiopsis causing leaf spots of Trachycarpus fortunei. Cryptogamie Mycologie 33, 1-8. 